\title{
A FORMAÇÃO CONTINUADA DE PEDAGOGOS EM EDUCAÇÃO AMBIENTAL EM DUAS ESCOLAS PÚBLICAS DO ESTADO DE SÃO PAULO
}

\author{
ENVIRONMENTAL EDUCATION CONTINUED FORMATION OF TEACHERS IN TWO PUBLIC \\ SCHOOLS IN THE STATE OF SÃO PAULO
}

\author{
Marcela de Moraes AGUDO* \\ Marília Freitas de Campos TOZONI-REIS**
}

\begin{abstract}
RESUMO: Este estudo apresenta o desenvolvimento de uma intervenção com inspirações na pesquisa-ação realizada junto de professores dos anos iniciais do Ensino Fundamental de duas escolas públicas estaduais do Estado de São Paulo. A proposta de inserção da educação ambiental na educação escolar nesta pesquisa foi problematizar possibilidades pedagógicas da educação ambiental a partir do conto infantil "A maior flor do mundo" de José Saramago. O objetivo deste trabalho é analisar os esforços de formação de dois grupos de professores e os aspectos que envolveram a formação desses professores na pesquisa realizada, propiciando a formação de educadores ambientais. As condições de precarização do trabalho pedagógico na organização da escola pública contemporânea constituem uma das dificuldades encontradas para que uma formação de professores aprofundada possa se concretizar. Portanto, consideramos necessário enfrentar a organização atual da escola pública e as condições de trabalho dos professores para uma educação ambiental emancipatória.
\end{abstract}

PALAVRAS-CHAVE: Educação ambiental. Escola pública. Formação de professores.

\begin{abstract}
This paper presents the development of an mediation inspired in actionresearch conducted with teachers of early years of elementary school in two public schools in the State of São Paulo. The proposal of including environmental education in school education in this research was discuss pedagogical possibilities of environmental education from the children's tale "The largest flower in the world" by José Saramago. The goal of this paper is to analyze the efforts of creating two groups of teachers and the aspects that involved the training of these teachers of the research, providing environmental educators training. The precarious conditions of educational work in the organization of nowadays public schools is one of the problems found to materialize a deep teacher training. Therefore, it is necessary to stand up to the current organization of public school and the working conditions of teachers for an emancipatory environmental education.
\end{abstract}

\section{Introdução}

Este estudo apresenta o desenvolvimento de um processo de investigação por meio de uma intervenção com inspiração nos fundamentos da pesquisa-ação realizado junto a

\footnotetext{
* Bióloga, Pedagoga, Mestre e Doutora em Educação para a Ciência, é pesquisadora do Grupo de Pesquisa em Educação Ambiental (GPEA), da Universidade Estadual Paulista “Júlio de Mesquita Filho”, Campus de Bauru.

* * Pedagoga, Doutora em Educação pela UNICAMP. É Professora Adjunta e líder do Grupo de Pesquisa em Educação Ambiental (GPEA), vinculado ao Programa de Pós-graduação em Educação para a Ciência da Universidade Estadual Paulista "Júlio de Mesquita Filho", Campus de Bauru.
} 
professores dos anos iniciais do Ensino Fundamental de duas escolas públicas estaduais de um município do interior do Estado de São Paulo. Neste trabalho, a estratégia de inserção da educação ambiental na educação escolar teve o conto infantil "A maior flor do mundo" de José Saramago como ponto de partida. O objetivo foi discutir a experiência vivenciada nos esforços de formação dos grupos de professores e nas atividades da pesquisa realizada que visaram propiciar a formação dos pedagogos como educadores ambientais, e as principais dificuldades encontradas na organização da escola pública para a formação grupal e a formação dos professores educadores ambiental.

Neste sentido, compreendemos a educação ambiental crítica que considera os princípios democráticos e emancipatórios para a prática educativa facilitadora da transformação social, proporcionando a formação de conhecimentos que promovam o desenvolvimento dos sujeitos nas relações da sociedade com o ambiente natural e social em que vivem, perspectiva que guiou esta pesquisa (LOUREIRO et al, 2012). Neste contexto, o educador ambiental torna-se um mediador entre o ambiente e as relações estabelecidas pelos grupos sociais, incluindo o grupo com que trabalha.

Além desta perspectiva crítica da educação ambiental, entendemos a escola pública como principal espaço para a educação ambiental transformadora, compreendendo esse espaço educativo contemporâneo como resultado de um processo social e histórico, repleto de contradições. Neste sentido, é importante considerar que existem enfrentamentos necessários para que seja construída coletivamente a escola pública de interesse popular.

Assim, considerando o caráter público da escola, da segunda metade do século $\mathrm{XX}$ até o século XXI, o Estado neoliberal vem trazendo novas acepções sobre o público e estatal, se afastando do compromisso com os serviços públicos e populares, apresentando ideias como as de terceiro setor e de parcerias público-privadas para esses serviços, como indica Saviani (2005). Com isso, a educação pública tornou-se, além de dever do Estado, dever também da sociedade, inserindo-se em um setor de serviços que não são exclusivos do Estado, possibilitando a atuação e inserção de interesses privados.

Como afirma Chauí (2003), a educação passou de direito da população à serviço prestado a essa população, ou seja, deixou de ser um serviço público e passou a ser considerada um serviço que pode ser privado ou privatizado. Neste sentido, a escola pública deixou de ser uma instituição social, que poderia se relacionar com a sociedade e com o Estado de maneira conflituosa e foi redefinida como organização social. 
Com a escola pública compreendida como organização social - e não como instituição social -, alguns pontos principais e primordiais para a qualidade socialmente referenciada da educação básica deixam de ser problematizados pelo Estado. Um desses pontos é a precarização do conteúdo dos materiais didáticos e outro, de grande importância, o da formação dos professores. Ambos revelam a educação pública que interessa ao Estado proporcionar à população, ou seja, uma escola "interessada" no sentido mais clássico, uma escola mantenedora dos interesses da classe dominante (ALVES, 2004).

Compreendendo que a problemática socioambiental é um ponto a ser problematizado e discutido neste espaço público, torna-se importante refletir que a educação ambiental crítica tem conteúdos fundamentais para compor o processo educativo. Considerando que a escola pública tem a função social de formar de maneira aprofundada os filhos da classe trabalhadora, tendo em vista sua prática social transformada e transformadora, a apropriação crítica de conhecimentos sobre as questões socioambientais é um aspecto fundamental. Considerando que os professores são os principais instrumentalizadores do processo de ensino e aprendizagem, a formação destes profissionais, por meio da apropriação de conhecimentos e fundamentos da educação ambiental crítica, se revela fundamental para a inserção da educação ambiental crítica na escola pública.

\section{A educação ambiental e os caminhos metodológicos e formativos com os professores}

Considerando que a pesquisa realizada foi qualitativa, em que os pesquisadores estudam a realidade em seu contexto tal e como se apresenta, nos inspiramos nos fundamentos da pesquisa-ação para a realização da intervenção junto dos grupos de professores. Com isso, consideramos o que Barbier (2004) discute sobre a pesquisa-ação emancipatória, quando indica três pontos essenciais dessa modalidade de pesquisa: que os pesquisadores técnicos, por exemplo os docentes de uma escola, percebam o processo educativo como um objeto passível de pesquisa; que estes pesquisadores percebam a natureza social e as consequências da reforma em curso; e que compreendam a pesquisa como uma atividade social e política.

De acordo com Tozoni-Reis (2005), a pesquisa-ação participativa pode criar condições de superação do cientificismo cartesiano. Para isso, é necessário levar em conta que esta metodologia tem um caráter político, pois garante a participação democrática dos sujeitos envolvidos, conectando a teoria e a prática. Os interesses científicos estão atrelados aos 
sociais, o que gera conhecimentos capazes de atenderem ao que os participantes precisam. $\mathrm{O}$ principal desafio da pesquisa-ação, segundo Thiollent (1999), é produzir novas formas de conhecimento e novos relacionamentos dos pesquisados e dos pesquisadores em relação ao saber, sendo necessária uma orientação crítica.

A educação ambiental crítica possibilita meios para transformação da realidade e a pesquisa-ação-participativa possibilita um meio de articulação radical entre a produção de conhecimentos e a participação dos envolvidos, com possibilidades de aprofundamento dos estudos, considerando a ruptura da dicotomia entre sociedade e natureza (TOZONI-REIS, 2005).

Brandão (2003) considera que o critério de confiabilidade de uma pesquisa não está apenas e principalmente no fundamento teórico, no emprego de métodos e na qualidade do produto final, está também em todo o processo de realização, avaliando deste processo a qualidade da interação entre as pessoas envolvidas. Com essas preocupações, esforços foram empreendidos para considerar os professores como sujeitos participantes parceiros de pesquisa.

A realidade da organização da escola pública, a formação dos professores e suas condições de trabalho possibilitaram que fosse realizada uma intervenção em que houve o processo de pesquisa e de formação de professores no sentido de uma educação ambiental emancipatória. A participação dos professores foi resultado das condições de trabalho precarizadas e a organização escolar que as envolvem, mas, mesmo assim, foi possível problematizar as possibilidades pedagógicas da educação ambiental na escola, inclusive a partir do conto "A maior flor do mundo" de José Saramago.

Assim, buscamos dar ênfase às análises realizadas a partir do processo formativo desenvolvido com os grupos de professores, dentro das possibilidades encontradas na realidade escolar, mais especificamente no horário das Aulas de Trabalho Pedagógico Coletivo (ATPC).

Assim, no decorrer da pesquisa, vários encontros foram feitos nas duas escolas, com pequenas diferenças que não foram significativas no desenvolvimento da pesquisa. Alguns dos problemas encontrados para o desenvolvimento pleno das atividades planejadas foram: pequeno período de tempo para o desenvolvimento das atividades; mudança do quadro de professores no final do ano; ATPC ocupado com informes burocráticos, diminuindo o tempo para o trabalho e o estudo coletivos; condição de precarização do professor; e a organização 
da escola pública. Mesmo nestas condições, com o interesse dos professores na educação ambiental, um processo formativo foi realizado junto deles.

A ênfase que foi dada no processo de formação dos professores pelo estudo, considerando a fundamentação pelo conteúdo de educação ambiental foi uma decisão coletiva e demanda principal dos professores. Neste sentido, foi decidido coletivamente que haveria um estudo dos fundamentos e dos conteúdos para desenvolver uma prática mais aprofundada da educação ambiental crítica. Com isso, em encontros realizados durante o momento do ATPC, quatro foram as principais atividades de estudos realizados junto dos professores, bem como a análise da apropriação dos conteúdos por eles, considerando as determinações e condições da realidade e do trabalho do professor na atual organização da escola pública.

A primeira atividade teve por objetivo investigar e considerar as concepções de educação ambiental dos professores. A atividade consistiu em trabalhar com tarjetas de papel, nas quais os professores expressavam o que consideravam como educação ambiental, por meio de algumas palavras ou termos. Isso repercute e se relaciona à concepção de educação ambiental que os professores possuem, gerando uma discussão a partir da atividade.

Em ambas escolas os professores indicaram termos diversos construídos a partir de suas vivências. As concepções mostraram o reconhecimento da importância da educação ambiental, por exemplo por meio dos termos "essencial", "necessária”, "hábito" e "urgente"; mas também demonstraram temas que são desenvolvidos considerados com frequência como educação ambiental: "reciclagem"; "conservar o meio ambiente"; "não fazer queimadas"; "cuidar do nosso planeta".

O objetivo desta primeira atividade foi provocar os professores para uma reflexão, a partir de questionamentos e apresentando outras maneiras, outros olhares para as questões que eles levantaram. Várias concepções dos professores foram identificadas, como a tendência da educação ambiental focada no ensino dos conteúdos de ecologia e ciências e a tendência da educação ambiental atitudinal ou comportamental, que se propõe a promover comportamentos ambientalmente adequados. Consideramos essas duas abordagens conservadoras, pois não problematizam as questões socioambientais em suas múltiplas determinações. Além disso, em alguns momentos, os professores revelaram perspectivas que tenta tratar as questões ambientais sem problematizar o contexto histórico, político, econômico e social que os determina. 
Tozoni-Reis (2008) sintetiza essas diferenças conceituais em grandes grupos: a educação ambiental de fundo disciplinatório e moralista, como "adestramento ambiental"; a educação ambiental centrada na transmissão de conhecimentos; e a educação ambiental transformadora e emancipatória.

É difícil que os professores compreendam que, para uma educação ambiental emancipatória, é necessário uma visão crítica, tentando compreender a realidade em sua essência. Um dos aspectos que mantém esta condição diz respeito às condições de trabalho dos professores em que não estão incluído um tempo destinado à atividade de estudo, uma condição fundamental para conseguirmos compreender a realidade para além das aparências, o que mostra a desvalorização e a falta de incentivo aos estudos para os professores das escolas públicas estaduais do Estado de São Paulo. Neste sentido, eles tem que seguir a lógica imposta nas instâncias burocráticas para a organização da escola pública, com receio de enfrentar essa organização que se mostra muito autoritária. Considerando que os professores são levados a trabalhar em diversas escolas, por conta do baixo salário que recebem, as condições para a organização coletiva, com a finalidade de reivindicar melhores condições de trabalho, por exemplo, são muito limitadas. Diante disso, estudar e se apropriar dos conhecimentos, exigência inerente ao trabalho do professor, tornam-se tarefas difíceis.

A segunda atividade desenvolvida com os grupos de professores foi análise do conto "A maior flor do mundo" e reflexão sobre as possibilidades de trabalho na sala de aula. A proposta de reescrita do conto foi desenvolvida pelos professores com seus alunos. Inicialmente, apesar de considerarem uma atividade importante, os professores participantes colocaram alguns obstáculos para essa atividade, considerando-a acima da capacidade dos alunos, com muitas "palavras difíceis".

Um ponto que se destacou foi que várias professoras acharam as ilustrações "feias" e "confusas". No entanto, o professor de Arte da Escola iniciou um debate com as professoras, comentando as imagens do livro e afirmando que o ilustrador mistura várias técnicas, entendendo que, em uma página somente, uma ilustração já renderia muito conteúdo, inclusive artístico, a ser trabalhado com os alunos. Com estas discussões, os professores começaram a ter um novo olhar para o conteúdo do conto e sua ilustração.

As análises e discussões sobre as atividades desenvolvidas junto aos professores como forma de contribuir para a formação em educação ambiental indicam a relação da teoria com a 
prática na formação dos professores como um aspecto importante. Como afirma Ribeiro (2001, p.41):

compreendamos que se, de um lado, a dimensão prática é que determina em última instância a teórica, de outro, a dimensão teórica determina, no caso, fortemente a dimensão prática.

Para pensar a práxis, é necessário reconhecer as possibilidades materiais de intervenção no mundo. Como aponta Konder (1996), é necessário que se desenvolva a atividade "crítico-prática". Pensando no trabalho do professor pela práxis, é necessário que ele questione suas próprias convicções compreendidas como naturais. A partir da teoria e da prática refletidas torna-se possível ir além das aparências. Ao confrontar teoria e prática a reflexão pode resultar na ação transformada que defendem as correntes críticas da educação ambiental.

Com isso, a relação entre teoria e prática está organicamente relacionada às condições de trabalho dos professores. Imersos em problemas como aviltamento salarial, condições de trabalho estafantes nas escolas e autoritarismo da direção escolar, uma prática pedagógica transformadora é um desafio e uma necessidade. Entendemos que o ATPC poderia ser um espaço para a discussão sobre a teoria e a prática, sobre a mobilização coletiva e política, de acordo com a reivindicação da categoria para criação deste momento no trabalho docente.

Enquanto os professores desenvolviam as atividades com o conto com seus alunos, no ATPC buscamos o estudo da educação ambiental para compreendermos seus fundamentos. $O$ texto escolhido nos grupos para estudo foi o de Sauvé (2005), pois aborda várias concepções de educação ambiental e foi considerado por todos o mais adequado para iniciar as reflexões sobre a educação ambiental, sendo esta a terceira atividade.

Uma corrente discutida pela autora e que foi apontada pelos professores foi a "recursista", e algumas questões sobre recursos naturais (preservacionista), gestão ambiental e consumismo foram debatidas. As professoras identificaram que esta é a perspectiva que vivemos e que precisa ser mudada. Na Escola Dois, uma professora considerou, em várias ocasiões, que as crianças não conseguem ter um olhar crítico da realidade, sendo bastante difícil o desenvolvimento desta perspectiva com os alunos dos anos iniciais do Ensino Fundamental.

Nas duas escolas, os professores identificaram as correntes que achavam mais pertinentes ao trabalho que precisava ser desenvolvido com a educação ambiental e ao que era 
desenvolvido na escola. Eles perceberam que a corrente que era desenvolvida na escola era a recursista e a corrente que mais lhes chamavam a atenção era a da sustentabilidade.

Mesmo com a argumentação em relação à corrente práxica ou à corrente crítica, que defende a transformação da realidade com a emancipação dos seres humanos, os professores se identificaram com a corrente da sustentabilidade baseada na ideia de "garantir um futuro melhor a todos". Sabemos que esta perspectiva é amplamente divulgada na grande mídia, uma das principais fontes de informações dos professores da educação básica para trabalharem com os temas ambientais junto a seus alunos, uma estratégia de promoção da ideologia hegemônica, que não tem nenhum compromisso com a transformação da realidade, ao contrário, objetiva sua reprodução (TOZONI-REIS, 2011).

O estudo de um segundo texto, de Tozoni-Reis (2008), foi escolhido para quarta atividade. Com a leitura e discussão deste texto, foram citados os pontos principais da educação ambiental enquanto um processo continuado, permanente, com estratégias específicas desenvolvidas pelos seus participantes. Uma professora da Escola considerou que a inserção da educação ambiental crítica não se daria somente realizando uma atividade pontual, mas que os conteúdos da educação ambiental precisam estar sempre na prática pedagógica dos professores.

Apesar da necessidade de inserir a educação ambiental crítica na escola, as estratégias, princípios e objetivos educativos não são os mesmos para todos. Considerando que as diferenças conceituais resultam da construção de diferentes práticas educativas ambientais (TOZONI-REIS, 2005), apesar das diferenças entre o entendimento do pesquisador e o entendimento dos professores acerca da educação ambiental crítica, não foram encontradas diferenças significativas entre as concepções de educação ambiental dos professores nas duas escolas que fizeram parte desse estudo.

Por meio do texto de Tozoni-Reis (2008), algumas concepções pedagógicas da educação ambiental foram debatidas com os professores. A primeira relacionada à educação ambiental conteudista e técnica, envolvendo ensino de ciências e ecologia, a segunda relacionada à educação ambiental comportamentalista, em que comportamentos ambientalmente adequados são, mais do que estimulados, "adestrados", e a terceira relacionada à educação ambiental que contextualiza, questiona e problematiza as questões socioambientais tendo em vista uma educação ambiental crítica, emancipatória e transformadora. 
Enquanto Sauvé (2005) produziu um mapeamento das correntes de educação ambiental que são desenvolvidas, Tozoni-Reis (2008), tendo como foco a educação ambiental escolar, trouxe para o debate com os professores a educação ambiental a partir das teorias pedagógicas tão discutidas no mundo da educação. Assim, na leitura e no estudo do texto de Tozoni-Reis (2008) os professores se sentiram mais provocados e incomodados, refletindo sobre os estudos anteriores. Destacamos que o processo de formação continuada de professores não promove uma catarse ou um salto qualitativo nos momentos em que as atividades são desenvolvidas, mas possibilitam uma compreensão mais crítica e aprofundada, um incômodo que promove o questionamento da realidade, para além de sua aparência.

\section{Considerações Finais}

Com o desenvolvimento dos dois grupos de professores e a formação continuada na intervenção realizada, alguns aspectos puderam ser compreendidos. Percebemos que, no lugar de uma formação e fundamentação teórica aprofundada, os professores demonstraram concepções espontaneístas acerca das questões socioambientais. É claro que precisamos considerar que, com as condições precárias de trabalho, o professor não tem condições materiais para aprimorar seus estudos sequer na área mais ampla da educação. Da mesma maneira, muitas vezes se questionam sobre o investimento pessoal em seus estudos, já que a organização da escola pública não os incentiva. Além disso, a formação inicial docente para a escola pública, na maioria das vezes, é realizada em instituições de ensino superior privadas que, mais do que formação de professores, são organizações comerciais que visam lucro e sucesso mercadológico, .

Assim, analisando criticamente as atividades desenvolvidas durante a realização dessa investigação, dois pontos emergem acerca da educação ambiental no ambiente escolar: não é possível fugir da discussão dos conteúdos da educação ambiental e das condições precárias de trabalho dos professores.

O conteúdo escolar sistematizando, também crítico, histórico e dialético pois, para a educação ambiental crítica, as relações teoria e prática e forma e conteúdo, são de grande importância no processo de sua inserção na escola. Para isso é necessário um processo educativo ambiental que permita a apropriação crítica de conhecimentos, atitude e valores políticos e históricos, possibilitando uma prática social transformada e transformadora. 
Refletindo sobre o processo de pesquisa e as atividades realizadas com os professores para sua formação, percebemos que as condições de trabalho dificultam o estudo e a apropriação de conhecimentos acerca de uma educação ambiental mais crítica. Neste sentido, a formação docente precária torna-se mais agravada. Apesar disso, os professores, em geral, avançaram no sentido de conhecerem outras concepções de educação ambiental e questionarem a si próprios sobre as perspectivas de educação ambiental naturalizantes e técnicas.

A partir das atividades realizadas, podemos concluir que o processo grupal vivenciado contribuiu para que debates e discussões acerca da educação ambiental revelem para os sujeitos participantes reflexões e dimensões da realidade sobre as quais não tinham se atentado. Assim, as discussões e problematizações realizadas no processo grupal proporcionam um desenvolvimento dos sujeitos que, em outro contexto ou condição, é dificultado.

A tentativa de aprofundamento teórico-metodológico realizada no processo formativo dos professores não garantiu a apropriação dos conteúdos críticos trabalhados, mas oportunizou uma possibilidade de questionamento. Um dos aspectos que influenciou neste processo foi justamente a organização da escola pública atual. Esta organização é rígida, exige burocracias dos professores, age hierarquicamente, aceitando e incentivando o professor "tarefeiro", tecnicista, o que dificulta ações que almejam uma reflexão política sobre a relação entre sociedade e natureza e a prática social dos alunos.

Da mesma maneira, as políticas públicas para a educação ambiental na escola são escassas e, quando aparecem pela via oficial do Estado, são desenvolvidas de maneira superficial no contexto escolar. Para o enfrentamento desta realidade, é necessário a implementação de políticas públicas no sentindo de formação dos professores para o aprofundamento de sua formação pedagógica geral, incluindo as questões socioambientais de maneira crítica. Por isso, é necessário um esforço no sentido de promover a formação permanente de professores, incluindo as discussões de educação ambiental.

A educação ambiental desenvolvida no ambiente escolar está bastante distante da educação ambiental que problematiza, que é crítica e questionadora. Isso mostra o quanto é necessário lutar por melhores condições de trabalho e de educação, e também por uma formação continuada de professores que possibilite a apropriação crítica dos fundamentos teórico-metodológicos da educação ambiental. 


\section{Agradecimento}

À FAPESP, pelo apoio financeiro à pesquisa. Processo no 2010/14349-7, Fundação de Amparo à Pesquisa do Estado de São Paulo (FAPESP).

\section{Referências}

ALVES, G. L. A produção da escola pública contemporânea. Campinas: Autores Associados; Campo Grande: UFMS, 2004.

BARBIER, R. A Pesquisa-Ação. Brasília: Liber Livro Editora, 2004. 159 p.

BRANDÃO, C. R. A pergunta a várias mãos: a experiência da pesquisa no trabalho do educador. São Paulo: Cortez, 2003.

CARVAlHO, I. C. de M. (Orgs.). Educação Ambiental: pesquisa e desafios. Porto Alegre: Artmed, 2005.

CHAUÍ, M. A universidade pública sob nova perspectiva. Conferência de abertura da $\mathbf{2 6}^{\mathbf{a}}$ Reunião Anual da ANPED. Poços de Caldas, MG, 05 de outubro de 2003. Revista Brasileira de Educação, 2003, nº 24, pp. 5-15.

KONDER, L. O futuro da filosofia da práxis: o pensamento de Marx no século XXI. Rio de Janeiro: Paz e Terra, 1996.

LOUREIRO, C. F. B.; Trein, E.; Tozoni-Reis, M. F. de C.; Novicki, V. Contribuições da teoria marxista para a educação ambiental crítica. Cadernos CEDES, Campinas, v. 29, n. 77, p. 81-97, 2012. https://doi.org/10.1590/S0101-32622009000100006

RIBEIRO, Maria Luisa Santos. Educação escolar: que prática é essa? Campinas, SP: Autores Associados, 2001.

SAUVÉ, L. Uma cartografia das correntes em Educação Ambiental. In: SATO, M.;

SAVIANI, D. História da escola pública no Brasil: questões para pesquisa. In: LOMBARDI, J. C.; SAVIANI, D.; NASCIMENTO, M. I. M. (Orgs.) A escola pública no Brasil: história e historiografia. Campinas: Autores Associados, 2005.

THIOLLENT, M. Notas para o debate sobre a pesquisa-ação. In: BRANDÃO, C. R. (Org.) Repensando a pesquisa participante. São Paulo: Brasiliense, 1999. p. 82-103.

TOZONI-REIS, M. F. de C. Metodologias aplicadas à Eucação Ambiental. 2 ed. Curitiba: IESDE Brasil S.A., 2008. p. 7-17.

TOZONI-REIS, M. F. de C. Pesquisa-Ação: Compartilhando saberes; Pesquisa e Ação educativa ambiental. In: FERRARO JÚNIOR, L. A. (Org.) Encontros e caminhos: formação 
de educadoras(es) ambientais e coletivos educadores, Brasília: Ministério do Meio Ambiente, 2005. p. 269-276.

TOZONI-REIS, M. F. de C. 2011. Educação e sustentabilidade: relações possíveis. Olhar de professor, Ponta Grossa, 14(2): 293-308, 2011. Disponível em <http://www.revistas2.uepg.br/index.php/olhardeprofessor>. Acesso em: 08 fev 2013. 